\title{
Article \\ Organizational Change Management in Higher Education through the Lens of Executive Coaches
}

\author{
Dimitrios Vlachopoulos
}

Citation: Vlachopoulos, D.

Organizational Change Management in Higher Education through the Lens of Executive Coaches. Educ. Sci. 2021, 11, 269. https://doi.org/10.3390/ educsci11060269

Academic Editor: James Albright

Received: 30 April 2021

Accepted: 26 May 2021

Published: 31 May 2021

Publisher's Note: MDPI stays neutral with regard to jurisdictional claims in published maps and institutional affiliations.
Faculty of Digital Media \& Creative Industries, Digital Society School, Amsterdam University of Applied Sciences, 1091 GM Amsterdam, The Netherlands; d.v.vlachopoulos@hva.nl

\begin{abstract}
This study investigated perceptions of organizational change management among executive coaches working with British higher-education leaders and factors that make leaders effective when managing change. This basic qualitative research used semi-structured interviews with eight executive coaches selected through purposeful sampling. As main challenges to efficient, inclusive change management, participants mentioned leaders' lack of a strategic vision or plan, lack of leadership and future leader development programs, and lack of clarity in decision-making. They recognized that leaders' academic and professional profiles are positively viewed and said that, with coaching and support in leadership and strategic planning, these people can inspire the academic community and promote positive change. Additional emphasis was given to the role of coaching in the development of key soft skills (honesty, responsibility, resiliency, creativity, proactivity, and empathy, among others), which are necessary for effective change management and leadership in higher education. The paper's implications have two aspects. First, the lessons of the actual explicit content of the coaches' observations (challenges to efficient change management and views of leaders); second, the implications of these observations (how coaching can help and what leaders need).
\end{abstract}

Keywords: higher education; qualitative research; organizational change management; academic leadership development; academic leadership

\section{Introduction}

The relevant literature of the last decade on characteristics and trends in universities show that university education has thoroughly transformed [1,2]. Uncertain funding, greater competition, and increased globalization are forcing universities to examine their governance and consider how they might set themselves up to better adapt to a fastchanging market. In this regard, they have to implement changes at all levels, and coaching has become a major tool to help higher-education leaders facilitate change and manage its outcomes $[3,4]$.

As regards substantive change, higher education is a paradox [5]. It is a field in which new ideas, solutions, and practices are constantly developing within different fields. Change is supported, and when research data contradict current beliefs or models, ideas are changed [6]. On the other hand, professors and managers in higher education consider it difficult to change practices and behaviors [7]. Executive coaching in this context aims to help university leaders achieve more clarity in their professional careers, increase their level of personal awareness, improve their skillset, and reach their full potential [8]. Specifically, for this study, we considered executive coaches as qualified professionals, external to the academic institution, who collaborate with academic leadership to support them clarify objectives, achieve their development goals, and unleash their potential. The anticipation and preparation of academic leaders for change and their development within their institutions to accomplish organizational objectives are the most important objectives of the executive coaches [9]. In this way, coaching helps leaders achieve institutional goals amid changing trends in higher education [10]. Executive coaches have thus become critical 
partners in this development process [11]. It is important to mention that executive coaches hold academic leadership accountable beyond a single event, supporting leaders' focus on the most important tasks and serving as strategic partners for implementation [12]. They focus on making academic leaders aware of their unique strengths, providing feedback, and improving their efficiency in managing and executing change [13].

This study sought to better understand coaches' perceptions of this process. These experts work with academic leaders in UK higher-education institutions (Vice Chancellors, Pro-Vice Chancellors, Deans, and Directors) as externally hired staff. So, the identification and understanding of the perspectives of these experts will provide useful information about the challenges and opportunities faced by higher-education leaders arguing for, implementing, and evaluating change, and will help identify and meet leaders' needs in terms of skills they require to manage changes in their institutions.

The research questions that guided our study are as follows:

- Which factors affect executive coaches' perceptions of organizational change in higher education in the United Kingdom?

- What are executive coaches' perceptions of the factors that impact leaders' efficiency when managing change in British higher education?

To understand the context and answer the identified research questions, we reviewed works in the related literature to extract and situate key concepts.

\section{Change Management}

\subsection{Conceptual Research}

Change affects all organizations. In the market, the fittest survive— "fittest" meaning those who manage change well [14]. Change management refers to how well companies manage change [15]. This depends on the people involved, the type of business conducted, and the action taken.

Change can foster the growth of individuals and organizations [16]. However, stakeholders often resist change and change management plans. According to Kovoor-Misra [17] and Stouten et al. [18], three facets must be considered to achieve successful change:

- Motivation of organization members;

- Internal and external sources of change;

- Change's association with organizational cohesiveness, consensus, and order.

It is more suitable if employees clearly understand the preparations needed for changes envisioned by management [19]. Management should examine whether there are adequate resources to monitor the progress of change until completion.

\subsection{Change Management Models}

Organizational change requires that the members of a group should adapt their behaviors to meet changes in the environment. A key success factor for all leaders to be successful during this change process is the development of a strategy for successful change. Two models for mediating implementation and leadership initiatives for change in complex organizations [20,21] will be presented, followed by additional information on change management. First, Lewin's change model is presented, since it has been widely used as the theoretical foundation for modern change models, including Edgar Schein's planned change theory [22], which is a landmark for current research in the field of organizational culture and identifies the artifacts, values and assumptions that lead to positive organizational change. Then, Kotter's model, which is another "classic" for the field of organization change, is described. According to relevant research [23], the following two models are recommended for the change management in university institutions, taking balances of power and politics that are characteristic parts of academic systems. 


\subsubsection{The Lewin Model}

Lewin, a social psychologist, pioneered organizational change modeling in 1947 . He explained organizational change by using the analogy of a block of ice changing shape, and he described a three-phase change process: freezing-transition-freezing [24]. The first phase involves preparing the organization to accept that change is necessary, which implies breaking down the status quo before developing a new way of operating. To achieve this goal, management must clearly indicate to members why existing ways cannot continue [25]. Often, this is achieved by presenting poor statistics (e.g., sales, user satisfaction, or retention). According to Burnes [24], to prepare an organization for change, it is necessary to challenge core beliefs, values, attitudes, and behaviors. Using the analogy of a building, Lewin says that it is necessary to examine and prepare to change the existing foundations; without this, the entire building may collapse. This first phase involves the greatest challenges and strongest negative reactions, as people feel their most off-balance and stressed. Forcing an organization-wide reconsideration of core beliefs can create a controlled crisis that can awaken an employee's motivation to seek a new core and new balance, generating the necessary engagement to affect meaningful change. Thus, after unfreezing the status quo, change is implemented.

\subsubsection{The Kotter Model}

Kotter's widely used model [26] lists eight actions necessary for successful change:

- Establish a sense of urgency.

The environment is analyzed for possible crises and opportunities. Kotter and Schlesinger [27] estimate that convincing 75\% of managers that change is needed is necessary. According to Mohamad Mouazen [28], this is the time for a bold and aspirational message of opportunity to communicate the importance of acting immediately.

- Form a powerful guiding coalition.

People involved in this coalition must be encouraged to work in teams and without a hierarchy; this coalition must be broad based to avoid any one person or group bearing the full burden of change. Teams should have a mix of skills and experience and encompass different departments [28]. This coalition will disseminate information to help the organizational community understand the change, delegate tasks, and assure the necessary support.

- Develop a vision.

Kotter [26] emphasizes that a vision is needed to guide the transformation, and strategies to realize the vision. A vision should be simple and should express the purpose of the change.

- Communicate the vision.

The change coalition must communicate the vision throughout the organization. Coherent and continuous communication can reduce the risk of contradictory messages [21].

- Empower action according to the vision.

This important step involves eliminating processes and factors that impede transformation, ideally without harming the organization's operations [26].

- Plan for and achieve short-term wins.

Graamans et al. [29] show that change often does not yield immediate reward and that this runs the risk of losing support from collaborators who come to feel their effort was wasted. As a solution, to keep people engaged, short-term wins are needed that tangibly demonstrate the advantages of the change.

- Consolidate improvements and maintain change.

Kotter [26] emphasizes that change can fail when change leaders become complacent. To address this, Hui [30] argues for the importance of maintaining and consolidating change for a long time after it has been achieved. 
- Institutionalize changes in corporate culture.

According to Kotter [26], changing organizational processes or employee habits is not always enough to achieve changes in organizational culture. Thus, key agents should stay on board, new employees should be trained in new processes and attitudes, and awareness of the change's importance should be maintained among all employees.

\subsection{Change in Higher Education}

European universities are adopting techniques from the private sector to manage change, in an approach called managerialism, which, however, institutions have not fully adapted [31]. In 2018, the European University Association gathered leaders from several universities to gain a picture of challenges around daily operations and strategies to bridge the gap between strategy and execution [32]. Pinheiro et al. [33] identified signs of change related to academic leadership moving from rotating systems, which involve election among peers, to a more managerial logic with top-down, order-giving, performance measurement, and appointed managers, constituting a new academic profession.

Rising student enrollment with insufficient resources negatively affects many UK universities [31], especially less select institutions, many of which have advised staff to expect job cuts during 2019 and 2020; remaining staff are also unsustainably overworked, and turnover is high [34]. Times Higher Education [35] reports that 19 British universities reported operating deficits during 2016/17, compared to seven universities the year before. Uncertainty due to Brexit and COVID-19 shows a clear need for change in university administration.

The literature on the higher-education change management in the UK $[3,36]$ emphasizes that, to facilitate change, British universities are adopting organizational development tools used by large companies. In 2007, the Higher Education Funding Council for England (HEFCE) financed a project [37] called "Enhancing Organisational Development in English Universities". The project discovered that $92 \%$ of institutions were involved in some organizational change process to improve operations.

In 2014, the government announced additional funding to universities to improve equity and diversity, modernize management, and foster the professional development of employees [38].

The "Self-Assessment Tool for People Management" [39] responds to British universities' obligation to publish an annual report on how their processes of change have evolved in order to receive government funding. The tool covers seven dimensions of people management included in the report:

- Fair remuneration and employment;

- Recruitment and retention;

- $\quad$ Size and composition of the workforce;

- Development of necessary skills among personnel;

- $\quad$ Leadership and change management;

- Occupational health, staff well-being, health, and safety;

- Performance management.

Evaluation questions accompany each dimension in order to validate institutions' priorities in terms of their strategic goals [40] based on checklists and examples and considering inputs, processes, results, and outputs [39]. This tool is managed by human resources departments and can be adjusted to individual institutions.

Based on the resulting reports between 2016 and 2018 [41-43], we identified priority topics for change management in the following areas:

- $\quad$ Leadership and development management: Lack of strategic plans and coordination for professional development of leaders in universities is present.

- $\quad$ Roles and titles: Better definition of academic admin roles (director, department secretary, dean, academic manager, etc.) is needed to better understand their contributions to change management. 
- Recruitment and retention: Insufficient data are available regarding decision-making processes.

- $\quad$ Role of the human resources department: HR's role in recruitment, change management, and employee evaluation is not always well-defined.

- Employee satisfaction surveys: More detailed surveys are needed, covering remuneration, professional development, and rewards.

\subsection{Synthesis of the Literature}

After analyzing the literature, we can see why choosing specific change strategies can be a complex undertaking for a university. Not all institutions have established processes based on corporate models [7], despite the robust literature on the subject [44]. Kotter and Schlesinger [27] offer three steps for choosing a change strategy:

- Analyze situational factors;

- Determine optimal rate of change;

- Consider methods to manage resistance to change.

A fourth item might be ensuring internal consistency of strategies.

Change in a company and in a university are similar in several ways, and employees are affected by poor change leadership in either sector. However, there are also several important differences. For example, publicly funded universities may respond to different logic than for-profit companies; in addition, although administrative offices are responsible for managing change, professors also actively participate in these processes.

Higher-education institutions often hire consultants and coaches to help with change [45]. Executive coaches have been shown to be effective when collaborating to develop the so-called "psychological needs" of the leader (competence, autonomy, and relatedness) through facilitating the leader's "self-discovery and purposeful action" [45]. University departments may also hire coaches to guide employees through change. This study investigates executive coaches' perceptions of change management and effective academic leadership in British universities.

\section{Research Methodology}

A basic exploratory qualitative design was used here [46,47]. This method was used to "answer direct questions without framing research within an explicit theoretical, philosophical, epistemological or ontological tradition" [48]; it is suitable for exploring "attitudes, opinions, beliefs or experiences of people" [49]. It was widely used in the recent literature and is considered appropriate when research questions are focused on discovering the "who", "what", and "where" of lived experiences [50] or when information is needed about a poorly understood situation [51]. Since our literature search did not show similar studies that had verified other methods in our context, we considered basic exploratory qualitative research the best choice.

Semi-structured interviews were used to collect rich data on participants' experiences [49]. The interview protocol was divided in three main sections: (a) demographic information of the participants, (b) questions related to the first research question (factors affecting the perceptions of the coaches on organizational change), and (c) questions related to the second research question (factors that impact leaders' efficiency when managing change in higher education). The interviews took place during the Spring semester of the academic year 2019/2020 (March-May 2020). Table 1 presents the characteristics and demographic information of the eight participants, who gave their written consent (Figure A1, Appendix A), before being interviewed. 
Table 1. Demographic information of the participating coaches.

\begin{tabular}{ll}
\hline Gender & 4 Male and 4 Female \\
\hline \multirow{3}{*}{ Age } & 2 between 30 and 39 years old \\
& 3 between 40 and 49 years old \\
& 2 between 50 and 59 years old \\
& 1 more than 59 years old \\
\hline \multirow{3}{*}{ Years of experience in coaching } & 2 between 3 and 4 years of experience \\
& 3 between 4 and 6 years of experience \\
& 2 between 6 and 8 years of experience \\
& 1 more than 8 years of experience \\
\hline \multirow{3}{*}{ Years of experience coaching academic leaders } & 2 between 3 and 4 years of experience \\
& 3 between 6 and 6 years of experience \\
& 1 more than 8 years of experience \\
\hline
\end{tabular}

More information on the types (research oriented/teaching oriented, geographical location, academic ranking, size, and so on) of universities that the academic leaders who worked with the participating coaches were affiliated with, will not be mentioned, in order to protect the anonymity and privacy of leaders and coaches. Erickson et al. [52] highlight that "the competence of senior managers is distributed randomly across the sector, and staff in any particular institution may simply be lucky or otherwise to have a good management team or a poor one" (p. 18).

The study followed data-analysis strategies established by Silverman [53] to examine the interview data. Silverman's technique follows an inductive approach in order to search for themes and patterns related to the research questions-this method is referred to as thematic content analysis [54]. After the data analysis, six themes were identified, three for each research question. Specifically, for the factors affecting coaches' perceptions on organizational change in higher education, the answers of the participating tutors were linked to the following themes: (a) strategy, (b) academic leadership development, and (c) decision-making process. For the factors affecting their perceptions on academic leadership efficiency, we identified the following themes: (a) traits of effective academic leaders, (b) training needs for effective academic leadership, and (c) acceptance of the academic leaderships by the wider community on campus. In this context, it is important to mention that, during the interviews, most the participants were eager to propose solutions for the challenges affecting their perceptions on organizational change in higher education. We found this feedback very valuable and "solutions" were included as an additional theme in the presentation of the findings.

Different verification strategies ensured the findings of this research met certain criteria of trustworthiness [49]. More analytically, we ensured credibility because the specific procedures employed, such as the line of questioning pursued during the interview sessions derived from other comparable qualitative research studies [55]. Moreover, we ensured transferability, since clear descriptions were utilized and data saturation occurred prior to the completion of all interviews [49]. Dependability and confirmability were accomplished by involving outside independent experts in evaluating and providing feedback on the identified themes, which enabled the comparison of multiple feedback loops. Two research methodology experts from the Open University of Catalonia (Spain) were consulted during the phases of data collection and data analysis.

We also used purposeful sampling, an ideal sampling approach for basic qualitative inquiries [56] as it yields participants with specific target experiences and thus provides greater confidence than a random sample of the same size. For identification of participants, we followed a "passive social media recruitment" approach [57] through a large LinkedIn group on coaching at work. The presence of the author in such group, through the role of mentor/coach and online faculty member aided the recruitment process. 
The participants were selected according to the following specific inclusion criteria: (a) they must be over 18 years old, (b) they must have had experience working as a coach for university leaders for three or more years, and (c) they must be employed in a professional coaching agency specializing in the higher-education sector. The selected people participated in semi-structured interviews of approximately 45-60 min. Data collection continued until saturation was reached. According to Ravitch and Carl [56], saturation is the point at which no new topics arise, generally occurring between eight and 12 interviews.

\section{Results}

Table 2 below presents a synthesis of topics identified during the data-analysis phase. Specifically, for the first research question (perceived change), three topics have been identified. Same applies for the second research question (the role of the leader in the process of change). These topics have been linked with direct quotations from the interviewees and have been discussed in the discussion and conclusion sections.

Table 2. Topics and subtopics identified in the data-analysis phase.

\begin{tabular}{ll}
\hline $\begin{array}{l}\text { Research Question 1. How do executive } \\
\text { coaches perceive change management in } \\
\text { higher education in the United Kingdom? }\end{array}$ & $\begin{array}{l}\text { Research Question 2. How do executive } \\
\text { coaches perceive the role of the leader in the } \\
\text { process of change in higher education in the } \\
\text { United Kingdom? }\end{array}$ \\
\hline Topic 1. Persons involved (title and function) & $\begin{array}{l}\text { Topic 1. Necessary skills (communication, } \\
\text { knowledge of strategic analysis, and other } \\
\text { soft skills) }\end{array}$ \\
\hline
\end{tabular}

Topic 2. Challenges (lack of strategic plans, need for systematic development of leaders, and reconsidering the

Topic 2. Leadership training decision-making process).

Topic 3. Solutions (more systematic planning; integration of support programs for academic leaders)

Topic 3. Acceptance of the leader

\subsection{Results Related to the First Research Question}

To investigate their perceptions of change management in higher education in the United Kingdom, participants were asked how their understanding of the processes and strategies followed by English universities for organization change management has evolved. Once the most important issues were identified, they were asked to explain their opinions with examples and lived experiences.

Before reflecting on how organizational change management is carried out in universities, the "key" roles (titles) of academics who participated in coaching sessions were identified. Specifically, all the participating coaches mentioned that, during their tenure spent coaching academic leaders, they had worked with vice-chancellors and pro-vice-chancellors at some time, while fewer had worked with executive vice-chancellors, directors, or deans.

- Strategy:

The participants were asked about the main challenges that these academic leaders faced when managing change. The main element that emerged in this regard during the interviews was the importance of having a strategic plan. Seven out of the eight participants, mentioned that the universities they worked with lacked a specific strategic plan for change management.

The participant who indicated that the university does have a strategic plan for change management explained its characteristics as follows:

There is a plan that defines the people leading the change management processes, the strategies to overcome resistance from the academic community, and a risk-assessment plan (P8). 
The purpose of these strategic plans was presented differently by each of the participants, but with consensus on their importance:

The goal of a strategic plan is to change the way they are currently doing things, with the hope that they can change their process and see better results by operating differently (P3).

The goal of a strategic plan is to manage the change process in a way that minimizes the introduction of mistakes and incidents related to change. It also ensures that standard methods and procedures are used so that changes can be addressed easily and with the least impact on the quality of service (P8).

Participants highlighted the benefits of a strategic plan for change management from different perspectives.

A strategic plan of change reinforces the behaviors necessary to create the culture that offers what the institutional strategy requires for success (P1).

A strategic plan provides direction and purpose for all change management activities. The plan outlines the unique characteristics of the change, its risks, and potential sources of resistance, ensuring that the entire community understands this process (P5).

With the strategic plan, leaders can analyze the changes they want to make and see how the different departments of the university are affected. The plan helps teams be ready in advance and guides them through the transition until the new reality becomes routine (P4).

- Academic-leadership development:

Another challenge mentioned by the participants was managing the development of academic leaders. The majority of the participants considered this aspect fundamental to successful change management:

An individual and organizational development model based on processes is important to guarantee lasting, concrete, and appropriate solutions for universities (P2).

The leaders and managers of the universities are under significant pressure to provide innovative higher education that better responds to the needs of society, but does not receive systematic support in this direction (P1).

Many times, academic leaders are in charge of management because of stellar performance in research or knowledge transfer, but that does not mean that they have the necessary skills to lead teams or the process of institutional change. They need help (P8).

- Decision-making process:

Finally, an important challenge that was discussed was the decision-making process in universities, which, according to most participants, is a prevalent theme, which lacks clarity and transparency:

Very small groups have the power to decide for the entire community, without the need to consult anyone (P1).

There is no specific model for decision-making processes, which often do not seem very transparent (P2).

Few people have access to the teams that make change decisions (P7).

Leaders do not receive any type of oversight regarding the decisions they make or the people they include in the decision-making process ( $\mathrm{P} 4)$.

- Solutions:

Of the solutions proposed by the participants for the aforementioned challenges, we highlight the need for more systematic planning:

Change management in universities needs a "road map" that identifies the beginning, the route to follow, and the destination. This map will integrate the resources, the scope or objective, and the costs involved in the plan (P6).

It is essential to provide a multistep process instead of sudden and unplanned "radical" changes (P8). 
Solid planning ensures that the university community has a clearer picture of the change and its value to all groups and departments. It will be easier to accept the change, and the communication about the process will be clearer and more transparent (P7).

The importance of introducing support programs through coaching was also highlighted:

Continuous coaching support can make the difference between simply learning and truly doing (P3).

An effective coach, whether it be human resources, an outside professional, or a mentor, can ensure a more efficient and democratic process of change (P4).

Coaching can help academic leaders make transformative changes and be more productive, gain control over their time, plan short- and long-term goals, and reconnect with the academic community (P8).

\subsection{Results Related to the Second Research Question}

- Traits of an effective academic leader:

Participants indicated the skills and competencies necessary to manage change. All participants began with the importance of communication:

Without a doubt, communication is fundamental to change management (P2).

Communicative competence is necessary to reduce employee resistance, increase motivation and morale, and receive higher-quality feedback from the different parties involved (P8).

Additionally, most participants mentioned that having vision is essential to successfully managing change:

Having vision is essential to helping the whole community see the direction they are moving in. That will motivate them more, without a doubt (P4).

The vision creates a story of change to follow and motivates everyone to be part of this change (P6).

Moreover, the majority of the participants indicated that an understanding of strategic analysis is essential for change management:

The soft skills we discussed are not enough. Leaders must be able to analyze the current state of the university and develop plans that will benefit it (P7).

Strategic thinking is fundamental because it permeates all aspects of the planning stage (P5).

Finally, participants mentioned additional soft skills that they considered necessary for change management led by the university community (Figure 1). Honesty, responsibility, and resiliency were the most popular soft skills, followed by proactivity, confirming the current research in the field. It is important to mention that the participants gave combinations of two or three soft skills in their responses with the combination "honesty, resiliency, and proactivity" being the most popular (three out of the eight participants).

- Training needs:

Reflecting on the training needs of academic leaders, participants emphasized the importance of coaching as a key element for the personal and professional development of staff who lead institutional changes. The types of coaching that would be most appropriate for managing changes in higher education were further specified.

First, most participants responded that "performance coaching" is what academic leaders need:

Leaders need coaching to better understand the requirements of their roles and functions, as well as the competencies and skills necessary to meet those requirements. In this way, they can fill the gap between what they are currently doing and the desired outcome (P8).

Coaches have to work with the management team of the universities in their workplace to help them understand what needs to be done and develop plans for their professional development (P1). 


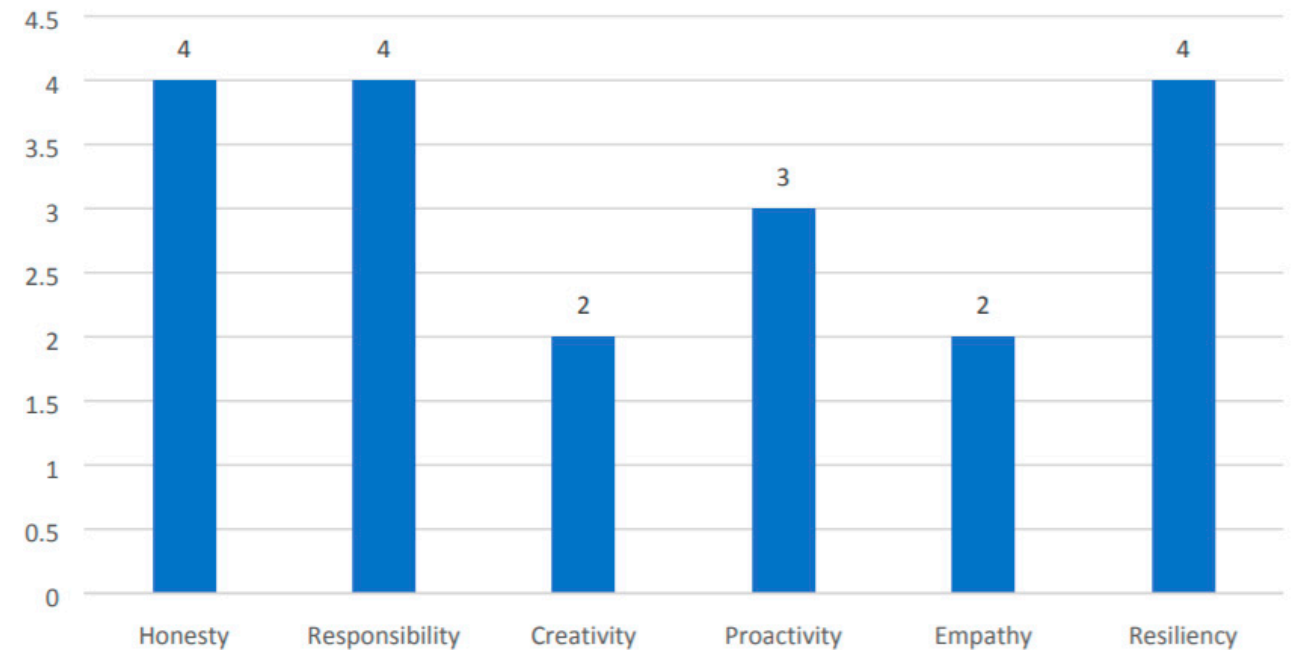

Figure 1. Skills needed for academic leaders to enact positive organizational change.

Most the participants emphasized the importance of high-potential coaching for academic leaders:

The coach is needed to help the academic leader develop their full potential since they are key to the future of their organization (P3).

The coaching program must ensure that the necessary competencies are developed, that there is continuous evaluation, and that one learns how to plan, structure, and implement strategic projects (P6).

Additionally, they mentioned the importance of succession-oriented coaching:

In most universities, we observe changes in the highest levels of management every five years. It is important to prepare people who have been identified as possible future leaders for their future functions (P2).

Many times, outsiders are hired for very important positions in a university. These people are unfamiliar with the institution, its values, its people, and its institutional culture. There is enough time from the selection of the candidates until their first official day in the position to adequately train them and prepare them for their work (P4).

- Acceptance of academic leadership:

Finally, an aspect mentioned by the majority of the participants was the acceptance of the management team by the rest of the academic community. The coaches have access to annual surveys that provide very interesting information on how staff perceive organizational culture, values, and the leadership team. Most coaches commented that change leaders who are accepted are, without exception, people of prestige in research, knowledge transfer, or innovation (having the rank of full professor).

On the other hand, the coaches also mentioned that the academic community itself does not always agree with the way leaders manage change. According to the coaches, this is also expressed by the leaders themselves, who receive much criticism on this issue. Specifically, most participating coaches mentioned that the academic leaders they work with do not feel accepted by the academic community of their institution as effective organizational change agents.

\section{Discussion}

The results obtained allow a critical reflection on the two research questions taken up in this study.

First, given the academic titles and categories of the leaders involved in change management, the majority of the academic community may feel marginalized in this process. The vice-chancellor, pro-vice-chancellor, and executive vice-chancellor are not easily accessible and do not interact regularly with students, professors, or, in general, 
with the daily reality of universities. Important positions, such as those of department director, academic secretary, or even dean, that are more linked to the daily workings of the campus, do not participate in change management processes, but are only recipients of the decisions made, and are asked to implement them in their departments and faculties. Wider participation seems necessary for more people to feel involved and motivated to facilitate processes of change [58], especially since "a decline across institutions in terms of democratic input and representation regarding university governance" has been observed [52]. Moreover, this wider participation is considered necessary to prepare the organization to accept the change by unfreezing the "status quo" of very few people involved in decision-making, as per Lewin's model.

As the main challenges to more efficient and inclusive change management, the participants mentioned the absence of a strategic vision or plan held by academic leaders, the lack of leadership and future leader development programs, and the lack of clarity in the decision-making process. Returning to the Kotter model [27], it is easy to see how these challenges inhibit the implementation of any of the eight steps. More specifically, the lack of a plan precludes a sense of urgency and complicates convincing other agents in the academic community, because a vision cannot be communicated without a plan. Surveys and current research [52] confirm the lack of evidence-based enterprise and decisionmaking by academic leaders at UK universities. Change leaders need to form a powerful coalition of members from the entire academic community, who must feel involved in the entire process and understand its value to the university and its operation. Lack of a strategic plan also does not allow planning for short-term wins that can motivate the academic community to follow and support the change process. Instead, lack of a plan generates frustration, insecurity, and lack of trust toward leaders [59]. According to Kotter [26], change in organizational processes or employee habits requires a change in organizational culture that is possible only if evidence of the benefits of the change is presented by leaders who inspire the rest of the community and if the entire process is transparent and inclusive.

In this context, the need for more systematic planning, the inclusion of more agents in the change management process, and the assurance of transparency in decision-making were presented as the keys to success by the participants in the study. To achieve all of this and implement the organizational strategy, resources and skills are needed to build a new reality while fully respecting the values of the organization and the expectations of the parties involved [60].

If we reflect on the competencies that the participants have identified, we find that the main focus is soft skills, confirming Aldulaimi [61], who considers them as keys towards effective performance across job categories, comparing to the technical skills. The leaders of the universities must follow a continuous process of ensuring effectiveness, with a focus on the progress of the educational process. Its success or failure is related to the type of relationship that exists between the leader and other agents (students, professors, and management personnel). This also confirms the literature on effective communication [62], since trust, mutual respect, positive influence, caring, and appreciation are key skills for successful communication. The leaders of educational institutions derive their importance from their ability to use all available means of innovation and creativity to adapt to the goals of the educational process and improve the performance of human resources [61]. Of course, soft skills alone are not enough to lead such complicated processes as organizational change of educational institutions; solid knowledge of strategic planning and resource management also seems to be indispensable to success [62].

Finally, it is important to continue to evaluate the role of coaching in change management in higher education. The participants emphasized three types of coaching: performance coaching, high-potential coaching, and succession-oriented coaching; these three types are considered to play a crucial role in the presence of leadership behaviors, such as support and training, to facilitate problem-solving and promote the success of people in an organization [45]. More specifically, the coaching experience allows change leaders to 
establish trust by creating a safe, transparent, and respectful environment [63]. Academic leaders need to further develop their active-listening abilities by focusing on what the academic community says and being aware of the emotions underlying those comments [64]. Finally, coaching will make leaders better able to ask impactful questions by challenging other people and taking responsibility for their own problems, since coaching will provide them with creative considerations and distinctive treatments for the challenges of higher-education experiences [65].

\section{Conclusions}

This study provides insight into the perceptions of coaches who work with leaders in the higher-education sector on the change management process and their role as leaders. Higher-education leaders are experts in a range of disciplines, with different levels of educational experience. Although they may have had success in research, innovation, teaching, or knowledge transfer, a comprehensive and unified approach to face the processes of organizational change is not yet evident. Exploring these issues in the contexts of institutions that work with coaches to guide leaders in such endeavors is important for evaluating the challenges and finding solutions that further meaningful change.

The results of this study provide a starting point from which to consider what knowledge, skills, and abilities are vital for university leaders to facilitate organizational change; the results thus inform the development of future leaders. Analysis of the participants' responses indicate that the academic and professional profiles of leaders were positively viewed and that, with support in the arenas of leadership, strategic planning, and soft skills, these people can inspire the academic community and promote the value and benefits of change management. The results of this study have thus helped identify gaps in the performance of academic leaders and point the way to possible development paths for future leadership education programs for academics.

Overall, this study supports the idea that academic leadership should lead and implement organizational change through the deeper understanding of the challenges identified by the coaches, as well as the personal and professional traits of effective academic leaders. The study further contributes towards this scope, through the solutions and training needs presented by the coaches, which can lead to effective leadership development programs.

Finally, future research should focus on discussing how coaches can help to bring forth what is known to be true in the literature about effective academic leadership and organizational change and how this can happen in institutions that do not have the financial means to hire an outside executive coach/consulting firm, since executive coaching is not an affordable option for all higher-education institutions. It would also be interesting to investigate the wider participation of academic leaders at other levels of the university in change processes.

Funding: This research received no external funding.

Institutional Review Board Statement: Not applicable.

Informed Consent Statement: See Appendix A.

Data Availability Statement: The data presented in this study are available on request from the corresponding author. The data are not publicly available due to the identify protection/confidentiality agreement with participants.

Conflicts of Interest: The author declares no conflict of interest. 


\section{Appendix A}

\section{PARTICIPANT CONSENT FORM}

Participant Name

Date

Signature

Title of Research Project: Leading change management in higher education. The perceptions of executive coaches

\section{Researcher: Dimitrios Vlachopoulos, PhD, SFHEA, FRSA}

1. I confirm that I have read and have understood the information sheet for the above study. I have had the opportunity to consider the information, ask questions and have had these answered satisfactorily.

2. I understand that my participation is voluntary and that I am free to withdraw at any time without giving any reason, without my rights being affected. In addition, should I not wish to answer any particular question or questions, I am free to decline.

3. I understand that, under the Data Protection Act, I can at any time ask for access to the information I provide and I can also request the destruction of that information if I wish.

4. I understand that confidentiality and anonymity will be maintained and it will not be possible to identify me in any publications.

5. I understand and agree that once I submit my data it will become anonymized, however I can ask to withdraw my data at any time.

To indicate that you consent to take part in this research please sign the consent form below. I consent to take part in the research titled: Leading change management in higher education. The perceptions of executive coaches.

Figure A1. Interview participant consent form.

\section{References}

1. Purcell, W.M.; Chahine, T. Leadership and governance frameworks driving transformational change in an entrepreneurial UK university. Leadersh. Organ. Dev. J. 2019, 40, 612-623. [CrossRef]

2. Phelps, A.; Vlachopoulos, D. Successful transition to synchronous learning environments in distance education: A research on entry-level synchronous facilitator competencies. Educ. Inf. Technol. 2019, 25, 1511-1527. [CrossRef]

3. Newby, H. The management of change in higher education. High. Educ. Manag. Policy 2003, 15, 9-22. [CrossRef]

4. Essel, H.B.; Vlachopoulos, D.; Adom, D.; Tachie-Menson, A. Transforming higher education in Ghana in times of disruption: Flexible learning in rural communities with high latency internet connectivity. J. Enterp. Commun. People Places Glob. Econ. 2021, 15, 296-312. [CrossRef]

5. Ahmad, T. Preparing for the future of higher education. Horizon 2015, 23, 323-330. [CrossRef]

6. Buller, J.L. Change Leadership in Higher Education: A Practical Guide to Academic Transformation; Jossey-Bass: San Francisco, CA, USA, 2015 
7. Hakro, A.N.; Mathew, P. Coaching and mentoring in higher education institutions: A case study in Oman. Int. J. Mentor. Coach. Educ. 2020, 9, 307-322. [CrossRef]

8. Athanasopoulou, A.; Dopson, S. A systematic review of executive coaching outcomes: Is it the journey or the destination that matters the most? Leadersh. Q. 2018, 29, 70-88. [CrossRef]

9. Bertrand, D.W. The practice of executive coaching to improve leadership capacity in academic deans at American higher education institutions. Coach. Int. J. Theory Res. Pract. 2018, 12, 110-124. [CrossRef]

10. Gray, J.A. Leadership coaching and mentoring: A research-based model for stronger partnerships. Int. J. Educ. Policy Leadersh. 2018, 13, 1-17.

11. Perry, E.; Boylan, M. Developing the developers: Supporting and researching the learning of professional development facilitators. Prof. Dev. Educ. 2017, 44, 254-271. [CrossRef]

12. Zenger, J.H.; Stinnett, K. Leadership coaching: Developing effective executives. Chief Learn. Officer 2006, 5, 44-47.

13. Nadeem, I.; Garvey, B. Learning experiences for academic deans: Implications for leadership coaching. Int. J. Evid. Based Coach. Mentor. 2020, 18, 133-151.

14. Kennerley, M.; Neely, A.; Adams, C. Survival of the fittest: Measuring performance in a changing business environment. Meas. Bus. Excel. 2003, 7, 37-43. [CrossRef]

15. Hiatt, J.; Creasey, T. Change Management: The People Side of Change; Prosci Research Learning Center Publications: Loveland, CO, USA, 2003.

16. Cohen, H. The change management fallacies. SAM Adv. Manag. J. 2019, 84, 4-15.

17. Kovoor-Misra, S. The impetus for resilience and change in business education and management research. J. Manag. Inq. 2019, 29, 128-133. [CrossRef]

18. Stouten, J.; Rousseau, D.M.; De Cremer, D. Successful organizational change: Integrating the management practice and scholarly literatures. Acad. Manag. Ann. 2018, 12, 752-788. [CrossRef]

19. Altaras, P.I. Change management in business organisation in the digital age. Acta Econ. Tur. 2019, 1, 79-81.

20. Hussain, S.T.; Lei, S.; Akram, T.; Haider, M.J.; Ali, M. Kurt Lewin's change model: A critical review of the role of leadership and employee involvement in organizational change. J. Innov. Knowl. 2018, 3, 123-127. [CrossRef]

21. Pollack, J.; Pollack, R. Using Kotter's eight stage process to manage an organisational change program: Presentation and practice. Syst. Pract. Action Res. 2014, 28, 51-66. [CrossRef]

22. Schein, E.H. Kurt Lewin's change theory in the field and in the classroom: Notes toward a model of managed learning. Reflect. SoL J. 1999, 1, 59-74. [CrossRef]

23. Shoham, S.; Perry, M. Knowledge management as a mechanism for technological and organizational change management in Israeli universities. High. Educ. 2009, 57, 227-246. [CrossRef]

24. Burnes, B. The origins of Lewin's three-step model of change. J. Appl. Behav. Sci. 2020, 56, 32-59. [CrossRef]

25. Tracy, J.A. Be a champion for change by using Lewin's 3-stage Model of Change. RDH 2020, 40, 18-20.

26. Kotter, J.P. Leading Change; Harvard Business School Press: Boston, MA, USA, 2011.

27. Kotter, J.P.; Schlesinger, L.A. Choosing strategies for change. Harv. Bus. Rev. 2008, 86, 106-114. Available online: https: / / search.proquest.com/docview/227820760?accountid=14872 (accessed on 10 May 2021).

28. Mohamad Mouazen, A. Transactional and Transformational Leadership Styles: Bibliometric Review, Relationship with Adkar and Kotter Change Models; Universitat Rovira I Virgili: Tarragona, Spain, 2019.

29. Graamans, E.; Aij, K.; Vonk, A.; Have, W.T. Case study: Examining failure in change management. J. Organ. Chang. Manag. 2020, 33, 319-330. [CrossRef]

30. Hui, A. Lean change: Enabling agile transformation through lean startup, Kotter and Kanban: An experience report. In Proceedings of the 2013 Agile Conference, Nashville, TN, USA, 28 July-1 August 2013; Available online: https:/ /ieeexplore.ieee. org/document/6612894 (accessed on 1 October 2020).

31. Dunning, M.J. Professional superheroes: Are changes in higher education stretching hospitality management academics' professionalism to the limit? J. Hosp. Leis. Sport Tour. Educ. 2019, 25, 100200. Available online: https://www.sciencedirect.com/ science/article/abs/pii/S1473837618302521 (accessed on 12 May 2021).

32. EUA. A Strategic Approach to Change for University Leaders. 2018. Available online: https://eua.eu/news/214:a-strategicapproach-to-change-for-university-leaders.html (accessed on 1 October 2020).

33. Pinheiro, R.; Geschwind, L.; Foss Hansen, H.; Pulkkinen, K. Reforms, Organizational Change and Performance in Higher Education; Palgrave Macmillan: Cham, Switzerland, 2019.

34. Markina, I.A.; Chykurkova, A.D.; Dudziak, O.A.; Opaliuk, T.; Dobrenko, I.A. Globalization-induced changes in higher education management in Ukraine. Int. J. Educ. Manag. 2019, 1291-1302. [CrossRef]

35. Times Higher Education. Growing English Deficits Trigger Sustainability Fears. 2018. Available online: https://www. timeshighereducation.com/news/growing-english-deficits-trigger-sustainability-fears (accessed on 1 October 2020).

36. Edgley-Pyshorn, C.; Huisman, J. The role of the HR department in organisational change in a British university. J. Organ. Chang. Manag. 2011, 24, 610-625. [CrossRef]

37. Higher Education Academy. Enhancing Organisational Development in English Universities; Higher Education Academy: York, UK, 2016. 
38. Robson, F.; Mavin, S. Evaluating training and development in UK universities: Staff perceptions. Eur. J. Train. Dev. 2014, 38, 553-569. [CrossRef]

39. McDonald, C. HEFCE's people management self-assessment tool. Perspect. Policy Pract. High. Educ. 2009, 13, 17-22. [CrossRef]

40. Purcell, W.M.; Beer, J.; Southern, R. Differentiation of English universities: The impact of policy reforms in driving a more diverse higher education landscape. Perspect. Policy Pract. High. Educ. 2015, 20, 24-33. [CrossRef]

41. HEFCE. HEFCE Annual Report and Accounts 2016-2017; HEFCE: London, UK, 2017.

42. HEFCE. HEFCE Annual Report and Accounts 2017-2018; HEFCE: London, UK, 2018.

43. HEFCE. HEFCE Annual Report and Accounts 2018-2019; HEFCE: London, UK, 2019.

44. Eckel, P.D. Assessing change and transformation in higher education: An essential task for leaders. Metrop. Univ. 2002, 13, 80-93.

45. Taylor, S.N.; Passarelli, A.M.; Van Oosten, E.B. Leadership coach effectiveness as fostering self-determined, sustained change. Leadersh. Q. 2019, 30, 101313. Available online: https:/ / weatherhead.case.edu/faculty/research/library/141319933952 (accessed on 3 May 2021). [CrossRef]

46. Merriam, S.B.; Tisdell, E.J. Qualitative Research: A Guide to Design and Implementation, 4th ed.; John Wiley \& Sons: San Francisco, CA, USA, 2015.

47. Moustakas, C. Phenomenological Research Methods; SAGE Publications, Inc.: London, UK, 1994.

48. Patton, M. Qualitative Research E Evaluation Methods: Integrating Theory and Practice; Sage Publications: London, UK, 2015.

49. Burkholder, G.; Cox, K.; Crawford, L.; Hitchcock, J. Research Design and Methods; Sage: London, UK, 2020.

50. Kim, H.; Sefcik, J.S.; Bradway, C. Characteristics of qualitative descriptive studies: A systematic review. Res. Nurs. Health 2017, 40, 23-42. [CrossRef] [PubMed]

51. Kahlke, R.M. Generic qualitative approaches: Pitfalls and benefits of methodological mixology. Int. J. Qual. Methods 2014, 13, 37-52. [CrossRef]

52. Erickson, M.; Hanna, P.; Walker, C. The UK higher education senior management survey: A statactivist response to managerialist governance. Stud. High. Educ. 2020, 1-18. [CrossRef]

53. Silverman, D. Interpreting Qualitative Data: Methods for Analyzing Talk, Text, and Interactions; Sage: Thousand Oaks, CA, USA, 1993.

54. Mendez, S.L.; Conley, V.M.; Keith, R.S.; Haynes, C.; Gerhardt, R. Mentorship in the engineering professoriate: Exploring the role of social cognitive career theory. Int. J. Mentor. Coach. Educ. 2017, 6, 302-316. [CrossRef]

55. Lincoln, Y.S.; Guba, E.G. Naturalistic Inquiry; Sage: Newbury Park, CA, USA, 1985.

56. Ravitch, S.; Carl, N. Qualitative Research: Bridging the Conceptual, Theoretical, and Methodological; Sage Publications: London, UK, 2016.

57. Gelinas, L.; Pierce, R.; Winkler, S.; Cohen, I.G.; Lynch, H.F.; Bierer, B. Using social media as a research recruitment tool: Ethical issues and recommendations. Am. J. Bioeth. 2017, 17, 3-14. [CrossRef]

58. He, Y.; Oxendine, S.D. Leading positive change in higher education through appreciative inquiry: A phenomenological exploration of the strategic planning process. J. High. Educ. Policy Manag. 2018, 41, 219-232. [CrossRef]

59. Albon, S.P.; Iqbal, I.; Pearson, M.L. Strategic planning in an educational development centre: Motivation, management, and messiness. Collect. Essays Learn. Teach. 2016, 9, 207-226. [CrossRef]

60. Ridley, D. Institutionalising critical pedagogy: Lessons from against and beyond the neo-liberal university. Power Educ. 2017, 9, 65-81. [CrossRef]

61. Aldulaimi, S.H. Leadership soft skills in higher education institutions. Soc. Sci. Learn. Educ. J. 2018, 3, 1-8. Available online: http://innovativejournal.in/index.php/sslej/article/view/2219/1838 (accessed on 14 May 2021). [CrossRef]

62. Vlachopoulos, D.; Makri, A. Online communication and interaction in distance higher education: A framework study of good practice. Int. Rev. Educ. 2019, 65, 605-632. [CrossRef]

63. Cruz, L.; LaNise, R. Coaching academia: The integration of coaching, educational development, and the culture of higher education. J. Excell. Coll. Teach. 2017, 28, 83-108.

64. Grant, A.M. The impact of life coaching on goal attainment, metacognition and mental health. Soc. Behav. Pers. Int. J. 2003, 31, 253-263. [CrossRef]

65. Saiti, A.; Abbott, I.; Middlewood, D. University governance: Insights from England and Greece. Int. J. Educ. Manag. 2018, 32, 448-462. [CrossRef] 